\title{
Exogenous melatonin ameliorates salinity-induced oxidative stress and improves photosynthetic capacity in sweet corn seedlings
}

\author{
D.Y. WANG, J. WANG, S.H. SHI, L.X. HUANG, M. ZHU', and F.H. LI \\ College of Agronomy, Specialty Corn Institute, Shenyang Agricultural University, 110866 Shenyang, Liaoning \\ Province, China
}

\begin{abstract}
Melatonin (MT) is involved in physiological processes in plants under abiotic stress. In this study, we investigated the effects of melatonin on maize photosynthetic and antioxidant capacities under salinity stress. Our findings indicated salinity stress significantly inhibited maize growth. However, exogenous MT promoted maize growth and antioxidant capacity. Superoxide dismutase, peroxidase, and catalase increased by $138.8,38.7$, and $32.0 \%$, respectively, while $\mathrm{H}_{2} \mathrm{O}_{2}$ and malondialdehyde decreased by 23 and 31\%, respectively. Exogenous MT also improved maize photosynthesis under salinity stress. Net photosynthetic rate, transpiration rate, and stomatal conductance increased by $134,67.2$, and $46.3 \%$, respectively. Maximum quantum yield of PSII photochemistry, effective quantum yield of PSII photochemistry, photochemical quenching coefficient, and electron transport rate increased by 5.8, 70.4, 65.3, and 41.0\%, respectively. Therefore, our findings suggested exogenous MT significantly ameliorated maize physiological and photosynthetic adaptation under salinity stress, thereby providing helpful guidance for maize cultivation in areas of high salinity.
\end{abstract}

Keywords: antioxidant enzymes; gas exchange; melatonin; salt tolerance; sweet corn.

\section{Introduction}

Abiotic stress factors have a great impact on agricultural productivity worldwide, of which, soil salinization is the most hazardous (Yu et al. 2015). Most crops are vulnerable to an increase in soil salinity; therefore, it is important to develop new strategies to manage salinity stress (Mahajan et al. 2020). Several studies have reported a significant decline in growth and biomass yield of plants under salinity stress (Ahanger et al. 2018, Alam et al. 2019). The effects of salinity stress on photosynthesis have several outcomes. A decrease in stomatal conductance leads to a decrease in carbon dioxide assimilation. Moreover, salinity stress is associated with a decrease in chlorophyll (Chl) content,

\section{Highlights}

- Exogenous melatonin (MT) mediated physiological and photosynthetic adaptation in sweet corn

- Exogenous MT maintained the balance of ROS metabolism under salinity stress

- Exogenous MT ameliorated salinity-induced damages of sweet corn seedlings
Received 21 January 2021

Accepted 17 May 2021

Published online 31 May 2021

${ }^{+}$Corresponding author

e-mail: xiaozhu211@syau.edu.cn (M.Zhu) lifenghai@126.com (F.H. Li)

Abbreviations: APX - ascorbate peroxidase; CAT - catalase; Chl - chlorophyll; $C_{\mathrm{i}}$ - intercellular $\mathrm{CO}_{2}$ concentration; $E$ - transpiration rate; EDTA - ethylenediamine tetraacetic acid; ETR - electron transport rate; FM - fresh mass; $\mathrm{F}_{\mathrm{v}} / \mathrm{F}_{\mathrm{m}}-$ maximum quantum yield of PSII photochemistry; $g_{\mathrm{s}}$ - stomatal conductance; MDA - malondialdehyde; MT - melatonin; NPQ - nonphotochemical quenching; $P_{\mathrm{N}}-$ net photosynthetic rate; POD - peroxidase; $\mathrm{q}_{\mathrm{P}}$ - photochemical quenching coefficient; ROS - reactive oxygen species; SOD - superoxide dismutase; TBA - thiobarbituric acid; TCA - trichloroacetic acid; WUE - water-use efficiency $\left(=P_{\mathrm{N}} / E\right) ; \Phi_{\text {PSII }}-$ effective quantum yield of PSII photochemistry.

Acknowledgments: We are grateful for grants from the National Key R\&D Program of China (2018YFD0300300, 2017YFD0300700, 2017YFD0101103).

Conflict of interest: The authors declare that they have no conflict of interest. 
damage to the photosynthetic organs, and changes in the activities of enzymes that participate in photosynthesis (Misra et al. 1997, Chaves et al. 2009).

Ahanger et al. (2018) concluded that a decrease in Chl content, net photosynthesis, stomatal conductance, and transpiration was observed in Solanum lycopersicum under salinity stress. Besides, Ahmad et al. (2019) showed that maximum quantum yield of PSII photochemistry $\left(\mathrm{F}_{\mathrm{v}} / \mathrm{F}_{\mathrm{m}}\right)$, the effective quantum yield of PSII photochemistry $\left(\Phi_{\mathrm{PSII}}\right)$, and photochemical quenching coefficient $\left(\mathrm{q}_{\mathrm{P}}\right)$ of mung bean plants decreased under $\mathrm{NaCl}$ stress, eventually leading to a reduction of photosynthesis. Reactive oxygen species (ROS) are produced when plants are exposed to adverse conditions (Kohli et al. 2019). Excessive accumulation of ROS leads to oxidative damage of lipids, proteins, and nucleic acids (Gao et al. 2015, Jbir-Koubaa et al. 2015), a reduction or loss in enzyme activity, lipid peroxidation of membranes (Bowler et al. 1992, Mittler 2002), and disruption of cell membrane integrity (Quintero et al. 2007, Farooq et al. 2015). There are enzymeprotection systems and nonenzyme-protection systems in plants that help remove a considerable extent of ROS that are produced under abiotic stress, thereby enhancing the adaptation of plants to stress (Allen 1995). The enzymes that are involved mainly include superoxide dismutase (SOD), peroxidase (POD), ascorbate peroxidase (APX), and catalase (CAT) (Meloni et al. 2003). SOD catalyzes the conversion of $\mathrm{O}_{2}{ }^{--}$to $\mathrm{O}_{2}$ and $\mathrm{H}_{2} \mathrm{O}_{2}$. The effective removal of $\mathrm{H}_{2} \mathrm{O}_{2}$ is catalyzed by POD and CAT ( $\mathrm{Li}$ et al. 2018). APX metabolizes $\mathrm{H}_{2} \mathrm{O}_{2}$ into $\mathrm{H}_{2} \mathrm{O}$ and $\mathrm{O}_{2}$ in plants and plays an important role in maintaining the balance of ROS in cells (Tyagi et al. 2020).

Melatonin was discovered in plants in the late 1990s (Zhang et al. 2015). It is a tryptophan derivative present in almost all organisms (Sharma and Zheng 2019). Melatonin is an excellent antioxidant, which can regulate the growth of roots, buds, and explants, activate seed germination, and delay leaf senescence in plants (Li et al. 2012, Arnao 2014). Previous studies indicate that foliar spray of MT can enhance the total fresh mass and dry mass of wheat plants under cadmium stress (Kaya et al. 2019). Melatonin participates in various physiological activities of different crops and protects plants from several abiotic stresses (Lee and Back 2018). Previous studies have reported that melatonin has a positive effect on various plants in alleviating environmental stress (Jiang et al. 2016, Liu et al. 2018). For instance, exogenous melatonin is known to reduce lipid peroxidation and alleviate cell membrane damage in kiwifruit seedlings subjected to water-shortage stress (Liang et al. 2019). In addition, exogenously applied MT has been shown to improve photosynthesis by increasing the content of Chl $a$ and $b$, as well as $\mathrm{F}_{\mathrm{v}} / \mathrm{F}_{\mathrm{m}}$ in the leaves of pepper plants (Capsicum annuum L.) subjected to either iron deficiency or salt stress, or in the case of combination stress (Kaya et al. 2020). Cucumber seedlings treated with melatonin have been reported to show a high rate of photosynthesis, which alleviates the effect of water stress (Zhang et al. 2013). Pretreatment with melatonin inhibits ROS burst, decreases MDA contents, and increases SOD, APX, CAT, and POD activities in tea plants under cold, salt, and drought stress (Li et al. 2019). Exogenous melatonin significantly alleviates the inhibition of osmotic stress on the growth of soybean seedlings and gas-exchange parameters. Moreover, the $\mathrm{Chl}$ content and photosynthetic rate of leaves were reported to have increased, potentially improving PSII efficiency (Zhang et al. 2019, Zou et al. 2019). Melatonin pretreatment significantly improves the drought tolerance of wheat seedlings, leading to a reduction in membrane damage and an increase in the rate of photosynthesis compared to the controls (Cui et al. 2017). Foliar spraying and direct root application of melatonin have been reported to alleviate damage to the photosynthetic organs and protect tomatoes from low-temperature stress (Yang et al. 2018). Some studies have also reported that the widely distributed nonenzymatic small molecule, melatonin, may help directly detoxify and maintain stable concentrations of hydrogen peroxide (Tan et al. 2000).

Sweet corn is a subspecies of Zea mays, which has excellent characteristics, such as high sugar content, unique flavor, and high contents of several nutrients necessary for the development of the human body. Thus, it is considered an important vegetable and economic crop worldwide (James et al. 1995, Feng et al. 2008). Sweet corn is easily influenced by high salinity, therefore, it is important to improve the salinity tolerance of sweet corn during cultivation. However, to the best of our knowledge, there are no reports on the alleviation of salinity stress in sweet corn by exogenous melatonin. Therefore, we studied the effects of exogenous melatonin on certain aspects of sweet corn seedlings under salinity stress. Accordingly, in this study, we evaluated the oxidative stress and photosynthetic characters of sweet corn under salinity stress. Further, we explored whether melatonin could improve the salinity stress tolerance of sweet corn seedlings. Additionally, we evaluated the protective role of melatonin in sweet corn seedlings under salinity stress in scavenging ROS, regulating the antioxidant activities of enzymes, and improving photosynthetic characteristics. Our findings could help clarify the alleviation of salinity stress of sweet corn by exogenous melatonin, and also shed light on devising methods for the cultivation of sweet corn in areas of high salinity.

\section{Materials and methods}

Plant material and experimental design: Zea mays L. saccharata Shen Tian No. 8, provided by the Specialty Corn Institute, Shenyang Agricultural Uni-versity, China, was used for this study. This study was carried out in 2020 at the Research and Education Center of Agronomy, Shenyang Agricultural University.

Full, pest-free sweet corn seeds were screened, surface sterilized with $0.5 \%$ sodium hypochlorite solution, washed five times with distilled water, and planted in a plug tray with cultivation substrate.

When the seedlings grew to the stage of two leaves, sweet corn seedlings of similar sizes were selected and transferred to a hydroponic container with Hoagland nutrient solution. Concentrations of $100 \mathrm{mM} \mathrm{NaCl}$ and 
$100 \mu \mathrm{M}$ MT were chosen for the current study based on our preliminary experiments (data not shown) and earlier published reports. For example, Hoagland's solution containing $100 \mathrm{mM} \mathrm{NaCl}$ simulates salinity stress in mung bean (Ahmad et al. 2019), whereas $100 \mu \mathrm{M}$ melatonin solution sprayed on Chinese licorice (Afreen et al. 2006) and tomato seedlings (Martinez et al. 2018) was found to be effective for tolerating abiotic stress. One day after transplantation, an appropriate amount of $\mathrm{NaCl}$ was added to the hydroponic container in Hoagland's nutrient solution to cause salt stress at a concentration of $100 \mathrm{mM}$. The seedlings were divided into the following four groups: (1) CK: normal control; (2) $\mathrm{NaCl}: 100 \mathrm{mM} \mathrm{NaCl}$; (3) MT: $100 \mu \mathrm{M}$ melatonin; (4) $\mathrm{NaCl}+\mathrm{MT}$ : $100 \mathrm{mM} \mathrm{NaCl}$ and $100 \mu \mathrm{M}$ melatonin. $\mathrm{NaCl}$ at a concentration of $100 \mathrm{mM}$ was added to the hydroponic container of all treatment groups to induce salinity stress. At 17:00 h, seedlings in the MT treatment group were sprayed with $100 \mu \mathrm{M}$ MT solution, and each hydroponic container was sprayed with $50 \mathrm{~mL}$ of this solution. The control group was sprayed with distilled water. All experiments in each group were performed three times. Samples were taken on day 5 of the $100 \mathrm{mM} \mathrm{NaCl}$ treatment and the relevant physiological indicators were determined.

Sampling and determination of growth parameters: After $\mathrm{NaCl}$ treatment for $5 \mathrm{~d}$, the third fully expanded leaves from the plant bottom were harvested, snap-frozen with liquid nitrogen, and stored at $-80^{\circ} \mathrm{C}$. Three sweet corn seedlings were randomly selected from each treatment group and washed with water. The aboveground and underground parts were separated. The measured indices included plant height and fresh mass (FM) of the shoots and roots. Next, the shoots and roots were transferred into the respective sample bags, dried in an oven at $105^{\circ} \mathrm{C}$ for $2 \mathrm{~h}$, and further dried to a constant mass at $80^{\circ} \mathrm{C}$. The dry mass (DM) of the shoots and roots was determined.

Gas-exchange parameters: A portable photosynthesis system LI-6800 ( $L i$-COR Inc., Lincoln, NE, USA) was used to measure the photosynthetic parameters of sweet corn seedlings. Photosynthesis of the third fully expanded leaves was measured using three individual plants per treatment. The net photosynthetic rate $\left(P_{\mathrm{N}}\right)$, stomatal conductance $\left(g_{\mathrm{s}}\right)$, transpiration rate $(E)$, and intercellular $\mathrm{CO}_{2}$ concentration $\left(C_{\mathrm{i}}\right)$ were measured in a controlled chamber $(1 \times 3 \mathrm{~cm})$ in an environment of $400 \mu \mathrm{mol}\left(\mathrm{CO}_{2}\right)$ $\mathrm{mol}^{-1}, 50 \%$ relative humidity, and PPFD of $1,500 \mu \mathrm{mol}$ $\mathrm{m}^{-2} \mathrm{~s}^{-1}$. Measurements were conducted between 10:00 and 11:00 h. Carboxylation efficiency $\left(P_{\mathrm{N}} / C_{\mathrm{i}}\right)$ was calculated based on $P_{\mathrm{N}}$ and $C_{\mathrm{i}}$, and the water-use efficiency (WUE) of sweet corn seedlings was calculated as $P_{\mathrm{N}} / E$ (Cai et al. 2020).

Chlorophyll (Chl) fluorescence: Chl fluorescence was measured using a fluorescence spectrometer (PAM2500, Walz, Germany) after the seedlings were allowed to adapt to the dark for $30 \mathrm{~min}$. The maximum quantum yield of PSII photochemistry $\left(\mathrm{F}_{\mathrm{v}} / \mathrm{F}_{\mathrm{m}}\right)$, nonphotochemical quenching (NPQ), the effective quantum yield of PSII photochemistry $\left(\Phi_{\mathrm{PSII}}\right)$, electron transport rate $(\mathrm{ETR})$, and photochemical quenching coefficient $\left(\mathrm{q}_{\mathrm{P}}\right)$ were measured. Chl fluorescence parameters were calculated according to the method reported by Perera-Castro et al. (2018).

Photosynthetic pigment contents: Chl was extracted and analyzed according to the method reported by Lichtenthaler and Wellburn (1983). Briefly, $0.1 \mathrm{~g}$ of fresh leaves were chopped finely, soaked in $10 \mathrm{~mL}$ of acetone, and left undisturbed in the dark for $48 \mathrm{~h}$. The absorbance at 645 and $663 \mathrm{~nm}$ was recorded using a microplate reader (Multiskan GO, Thermo Fisher Scientific, USA), and acetone was used as a blank. The following formulae were used for calculations: $\mathrm{Chl} a\left[\mathrm{mg} \mathrm{g}^{-1}(\mathrm{FM})\right]=\left(12.7 \times \mathrm{OD}_{663}-\right.$ $\left.2.69 \times \mathrm{OD}_{645}\right) \times \mathrm{V} /(1,000 \times \mathrm{M}), \mathrm{Chl} b\left[\mathrm{mg} \mathrm{g}^{-1}(\mathrm{FM})\right]=$ $\left(22.9 \times \mathrm{OD}_{645}-4.68 \times \mathrm{OD}_{663}\right) \times \mathrm{V} /(1,000 \times \mathrm{M}), \mathrm{Chl}(a+b)$ $\left[\mathrm{mg} \mathrm{g}^{-1}(\mathrm{FM})\right]=\mathrm{Chl} a+\mathrm{Chl} b$, where $\mathrm{OD}_{645}$ and $\mathrm{OD}_{663}$ represent the absorbances of $\mathrm{Chl}$ at the corresponding wavelengths, $\mathrm{V}$ is the total volume of the extract, and $\mathrm{M}$ represents the mass of the sample.

MDA and $\mathrm{H}_{2} \mathrm{O}_{2}$ : MDA was measured following the method reported by Hodges et al. (1999). Briefly, $0.5 \mathrm{~g}$ of fresh leaves were ground with $5 \mathrm{ml}$ of $5 \%$ trichloroacetic acid (TCA) in a mortar, and the extract was centrifuged for $5 \mathrm{~min}$ at $3,000 \times \mathrm{g}$. Next, $2 \mathrm{~mL}$ of the supernatant was taken in a $5-\mathrm{mL}$ centrifuge tube and $2 \mathrm{~mL}$ of $0.67 \%$ thiobarbituric acid (TBA) was added. The sample was mixed well, and the tube was immersed in a boiling-water bath for $30 \mathrm{~min}$ and re-centrifuged after cooling. The absorbance of the supernatant was determined at 532, 600, and $450 \mathrm{~nm}$ using a microplate reader (Multiskan GO, Thermo Fisher Scientific, USA). $\mathrm{H}_{2} \mathrm{O}_{2}$ was measured following the method reported by Xia et al. (2009). Briefly, $0.5 \mathrm{~g}$ of fresh leaves were homogenized with $5 \mathrm{~mL}$ of $0.1 \%(\mathrm{w} / \mathrm{v})$ TCA in an ice bath. After centrifugation at $12,000 \times g$ for $15 \mathrm{~min}, 0.5 \mathrm{~mL}$ of the supernatant was added to $0.5 \mathrm{~mL}$ of $10 \mathrm{mM}$ potassium phosphate buffer $(\mathrm{pH}$ 7.0) and $1 \mathrm{~mL}$ of $1 \mathrm{M}$ potassium iodide. The absorbance of the supernatant at $390 \mathrm{~nm}$ was recorded using a microplate reader (Multiskan GO, Thermo Fisher Scientific, USA).

Antioxidant enzyme activities: About $0.1 \mathrm{~g}$ of fresh leaves were homogenized with $5 \mathrm{~mL}$ of phosphate buffer (0.05 mM, pH 7.5) containing $0.05 \mathrm{mM}$ EDTA and $2 \%(\mathrm{w} / \mathrm{v})$ insoluble polyvinylpyrrolidone in an ice bath. For the determination of APX (EC 1.11.1.11), $1 \mathrm{mM}$ of ascorbic acid was added to this mixture. Each homogenate was centrifuged at $1,000 \times \mathrm{g}$ for $20 \mathrm{~min}$ at $4^{\circ} \mathrm{C}$ and the absorbance of the supernatant was measured using a microplate assay (Multiskan GO, Thermo Fisher Scientific, USA) to calculate antioxidant enzyme activities. SOD (EC 1.15.1.1) activity was calculated according to the method reported by Abedi et al. (2010). Three $\mathrm{mL}$ of the reaction mixture containing $14.5 \mathrm{mM}$ methionine, $75 \mathrm{mM}$ NBT, $2 \mathrm{mM}$ riboflavin, $0.1 \mathrm{mM}$ EDTA and $0.1 \mathrm{~mL}$ enzyme extract were illuminated for $10 \mathrm{~min}$ at a light intensity of $90 \mu \mathrm{mol} \mathrm{m}{ }^{-2} \mathrm{~s}^{-1}$. The activity of SOD was determined by 
measuring the inhibition of NBT photochemical reduction by enzyme extract at $560 \mathrm{~nm}$. One SOD activity unit was defined as the amount of enzyme needed to inhibit the photochemical reduction of NBT by $50 \%$. The SOD activity was expressed as SOD $\mathrm{U} \mathrm{mg}^{-1}$ (protein). APX activity was determined according to the method reported by Nakano and Asada (1981). The 3-mL reaction mixture contained $50 \mathrm{mM}$ potassium phosphate buffer $(\mathrm{pH} \mathrm{7.8)}$, $0.3 \mathrm{mM}$ ascorbate, $0.06 \mathrm{mM} \mathrm{\textrm {H } _ { 2 } \mathrm { O } _ { 2 } , 0 . 1 \mathrm { mM } \text { EDTA-Na }}$, and $0.1 \mathrm{~mL}$ enzyme extract, and the absorbance change at $290 \mathrm{~nm}$ was measured at $25^{\circ} \mathrm{C}$ when $\mathrm{H}_{2} \mathrm{O}_{2}$ was added. One unit of APX activity was defined as $1 \mu \mathrm{mol}$ of ascorbate oxidized per minute per mg of protein. APX activity was expressed as APX U mg-1(protein). CAT (EC 1.11.1.6) activity was determined using the procedure described by Wang (1995). The activity of POD (EC 1.11.1.7) was measured according to Rao et al. (1996) at $470 \mathrm{~nm}$ in $2 \mathrm{~mL}$ of a reaction mixture containing $100 \mathrm{mM}$ potassium phosphate buffer $(\mathrm{pH} 6.0), 0.25 \%(\mathrm{w} / \mathrm{v})$ guaiacol, $0.1 \mathrm{~mL}$ of $0.75 \%(\mathrm{w} / \mathrm{v}) \mathrm{H}_{2} \mathrm{O}_{2}$, and $0.1 \mathrm{~mL}$ of enzyme extract. One unit of POD activity was defined as $1 \mu \mathrm{g}$ of substrate catalyzed per minute per mg of protein. POD activity was expressed as POD $\mathrm{U} \mathrm{mg}^{-1}$ (protein).

Statistical analysis: All data were analyzed using $I B M$ SPSS 22.0 and differences between treatment groups were compared using Duncan's multiple range tests at the 0.05 level of confidence using one-way analysis of variance $(A N O V A)$. Data are expressed as mean \pm standard deviation (SD). Graphs were plotted using Origin 2019 software.

\section{Results}

Plant growth and biomass: Under normal conditions (without salinity stress), the addition of MT had no significant effect on plant height and biomass of sweet corn (Table 1). Salinity stress significantly inhibited the growth of sweet corn seedlings. Compared to CK, the plant height, shoot FM, shoot DM, and root DM were reduced significantly by $14.1,35,22.2$, and $40 \%$, respectively. On the contrary, spraying the seedlings with exogenous MT effectively improved the growth and biomass accumulation of sweet corn under salinity stress. $\mathrm{NaCl}+\mathrm{MT}$ treatment resulted in a significant and substantial increase in shoot FM and shoot DM (20.7 and $28.5 \%$, respectively) compared to stress treatment with $\mathrm{NaCl}$ alone; root FM and root DM increased by 39.1 and $44.4 \%$, respectively.
Photosynthesis: Salinity stress negatively affected the photosynthesis capacity of the leaves of sweet corn seedlings (Fig. 1). Under salinity stress, the $P_{\mathrm{N}}, E, g_{\mathrm{s}}$, $P_{\mathrm{N}} / C_{\mathrm{i}}$, and WUE of sweet corn seedlings were found to decrease by $81.2,60.5,58.3,88.8$, and $52.3 \%$, respectively, compared to the control. Nevertheless, the $C_{\mathrm{i}}$ was found to significantly and substantially increase by $68.1 \%$ in comparison with the control. However, the application of exogenous MT reversed the inhibitory effects of salinity stress and significantly $(P<0.05)$ increased the $P_{\mathrm{N}}, E$, $g_{\mathrm{s}}, P_{\mathrm{N}} / C_{\mathrm{i}}$, and WUE of the seedlings by $134,67.2,46.3$, 290.9 , and $40.4 \%$, respectively, relative to the salinity stress induced by $\mathrm{NaCl}$ treatment. The $C_{\mathrm{i}}$ of $\mathrm{NaCl}+\mathrm{MT}$ was found to decrease by $39.8 \%$ in comparison with the $\mathrm{NaCl}$ treatment.

Chl fluorescence parameters: $T$ The $\mathrm{F}_{\mathrm{v}} / \mathrm{F}_{\mathrm{m}}, \Phi_{\mathrm{PSII}}, \mathrm{q}_{\mathrm{P}}$, and ETR of sweet corn seedlings decreased under salinity stress (Fig. 2). Compared with $\mathrm{CK}, \mathrm{NaCl}$ treatment significantly decreased the $\mathrm{F}_{\mathrm{v}} / \mathrm{F}_{\mathrm{m}}, \Phi_{\mathrm{PSII}}, \mathrm{q}_{\mathrm{P}}$, and ETR values by 3.1 , $12.1,30.5$, and $39.6 \%$, respectively. The NPQ after $\mathrm{NaCl}$ treatment significantly increased by $17.2 \%$. Under normal conditions, there were no significant differences in the fluorescence parameters between the CK and MT groups. However, exogenous melatonin significantly improved $\mathrm{F}_{\mathrm{v}} / \mathrm{F}_{\mathrm{m}}, \Phi_{\mathrm{PSII}}, \mathrm{q}_{\mathrm{P}}$, and ETR under salinity stress. Relative to the stress induced by $\mathrm{NaCl}$, treatment with $100 \mu \mathrm{M}$ melatonin significantly increased the $\mathrm{F}_{\mathrm{v}} / \mathrm{F}_{\mathrm{m}}, \Phi_{\mathrm{PSII}}, \mathrm{q}_{\mathrm{P}}$, and ETR by 5.8 , $70.4,65.3$, and $41.0 \%$, respectively, suggesting the crucial role of MT in maintaining the efficiency of photosynthesis under salinity stress.

Chl content: Salinity stress significantly decreased the Chl $a$, Chl $b$, and $\mathrm{Chl}(a+b)$ contents by $24.7,24.3$, and $24.6 \%$, respectively, compared to the control (Fig. 3). However, MT treatment alleviated salinity stress and reduced the rate of $\mathrm{Chl}$ decomposition. $\mathrm{NaCl}+\mathrm{MT}$ treatment resulted in a significant and substantial improvement in the contents of Chl $a, \mathrm{Chl} b$, and $\mathrm{Chl}(a+b)$, which increased by $43.2,45.6$, and $43.9 \%$, respectively, compared to sweet corn seedlings subjected to salinity stress.

$\mathrm{H}_{2} \mathrm{O}_{2}$ contents and lipid peroxidation: Under normal conditions, there were no significant differences in $\mathrm{H}_{2} \mathrm{O}_{2}$ and MDA contents between the CK and MT groups. During salinity stress in sweet corn seedlings, high concentrations of $\mathrm{H}_{2} \mathrm{O}_{2}$ and MDA were determined; however, the

Table 1. Effects of melatonin on the growth and biomass of sweet corn under salinity stress. CK - normal control; $\mathrm{NaCl}$ - treatment with $100 \mathrm{mM} \mathrm{NaCl}$; MT - treatment with $100 \mu \mathrm{M}$ melatonin; $\mathrm{NaCl}+\mathrm{MT}$ - treatment with $100 \mathrm{mM} \mathrm{NaCl}$ plus $100 \mu \mathrm{M}$ melatonin. Values are expressed as mean $\pm \mathrm{SD}$ of three replicates. For each variable, means with different lowercase letters were significantly different $(P<0.05)$.

\begin{tabular}{llllll}
\hline Treatment & Plant height $[\mathrm{cm}]$ & Shoot fresh mass $[\mathrm{g}]$ & Root fresh mass $[\mathrm{g}]$ & Shoot dry mass [g] & Root dry mass [g] \\
\hline $\mathrm{CK}$ & $28.2 \pm 1.48^{\mathrm{a}}$ & $1.94 \pm 0.33^{\mathrm{a}}$ & $1.10 \pm 0.33^{\mathrm{ab}}$ & $0.18 \pm 0.02^{\mathrm{a}}$ & $0.15 \pm 0.03^{\mathrm{a}}$ \\
$\mathrm{NaCl}$ & $24.2 \pm 1.09^{\mathrm{c}}$ & $1.35 \pm 0.16^{\mathrm{c}}$ & $0.97 \pm 0.29^{\mathrm{b}}$ & $0.14 \pm 0.01^{\mathrm{b}}$ & $0.09 \pm 0.01^{\mathrm{b}}$ \\
$\mathrm{MT}$ & $27.0 \pm 2.22^{\mathrm{ab}}$ & $2.02 \pm 0.37^{\mathrm{a}}$ & $1.22 \pm 0.30^{\mathrm{ab}}$ & $0.17 \pm 0.01^{\mathrm{a}}$ & $0.14 \pm 0.01^{\mathrm{a}}$ \\
$\mathrm{NaCl}+\mathrm{MT}$ & $25.9 \pm 1.09^{\mathrm{bc}}$ & $1.63 \pm 0.27^{\mathrm{b}}$ & $1.35 \pm 0.40^{\mathrm{a}}$ & $0.18 \pm 0.01^{\mathrm{a}}$ & $0.13 \pm 0.02^{\mathrm{a}}$ \\
\hline
\end{tabular}



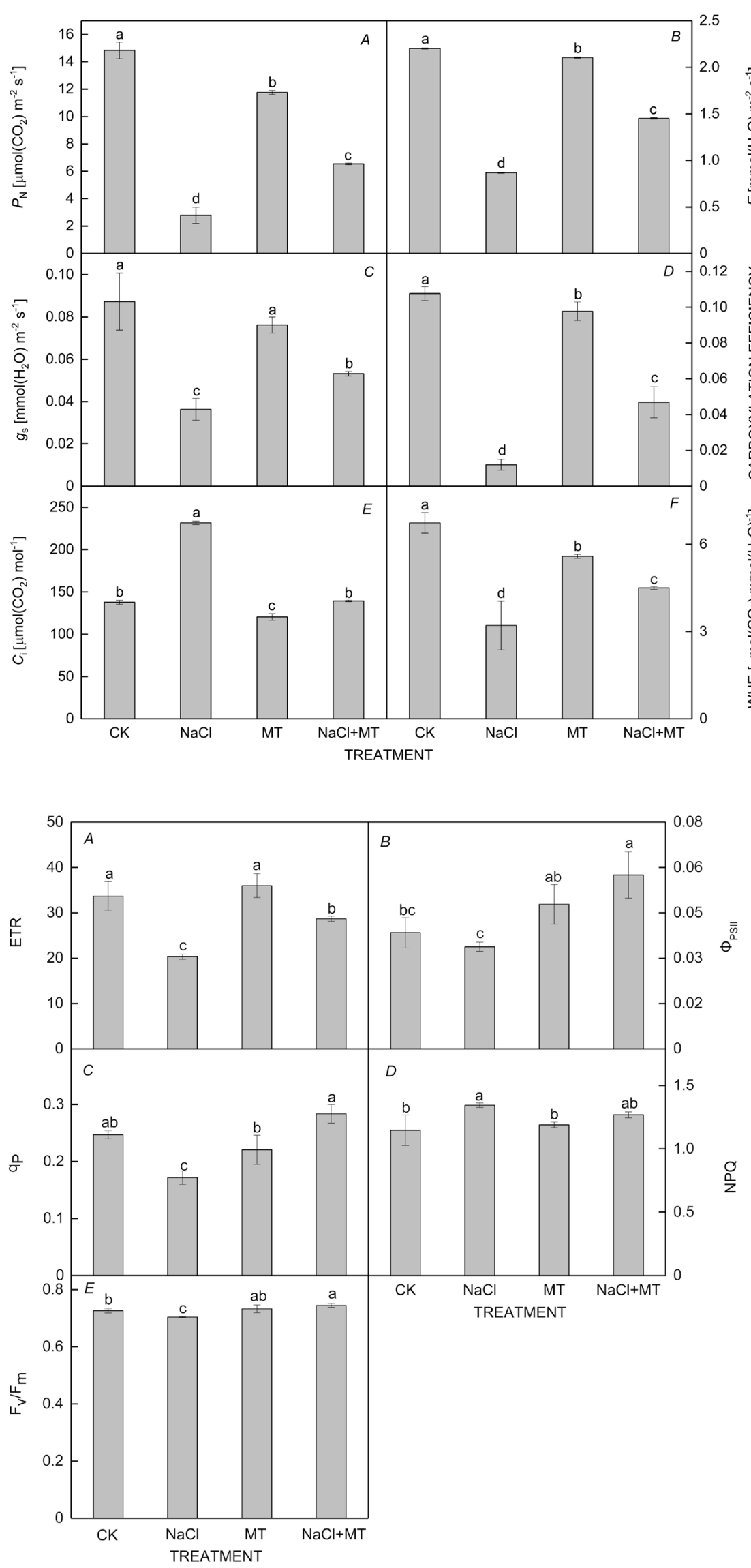

Fig. 1. Effect of melatonin on the net photosynthetic rate $\left(P_{\mathrm{N}}\right)(A)$, transpiration rate $(E)(B)$, stomatal conductance $\left(g_{\mathrm{s}}\right)(C)$, carboxylation efficiency $(D)$, intercellular $\mathrm{CO}_{2}$ concentration $\left(C_{\mathrm{i}}\right)(E)$, and water-use efficiency (WUE) $(F)$ of sweet corn leaves under salinity stress. $\mathrm{CK}$ : normal control; $\mathrm{NaCl}$ : treatment with $100 \mathrm{mM} \mathrm{NaCl}$; MT: treatment with $100 \mu \mathrm{M}$ melatonin; $\mathrm{NaCl}+\mathrm{MT}$ : treatment with $100 \mathrm{mM} \mathrm{NaCl}$ plus $100 \mu \mathrm{M}$ melatonin. Values are expressed as mean $\pm \mathrm{SD}$ of three replicates. For each variable, means with different lowercase letters were significantly different $(P<0.05)$.

Fig. 2. Effect of melatonin on the electron transport rate (ETR) $(A)$, effective quantum yield of PSII photochemistry $\left(\Phi_{\mathrm{PSII}}\right)(B)$, photochemical quenching coefficient $\left(\mathrm{q}_{\mathrm{p}}\right)(C)$, nonphotochemical quenching (NPQ) $(D)$, and maximum quantum yield of PSII photochemistry $\left(\mathrm{F}_{\mathrm{v}} / \mathrm{F}_{\mathrm{m}}\right)(E)$ of sweet corn leaves under salinity stress. CK - normal control; $\mathrm{NaCl}$ - treatment with $100 \mathrm{mM} \mathrm{NaCl}$; MT - treatment with $100 \mu \mathrm{M}$ melatonin; $\mathrm{NaCl}+\mathrm{MT}$ - treatment with $100 \mathrm{mM}$ $\mathrm{NaCl}$ plus $100 \mu \mathrm{M}$ melatonin. Values are expressed as mean \pm SD of three replicates. For each variable, means with different lowercase letters were significantly different $(P<0.05)$. 


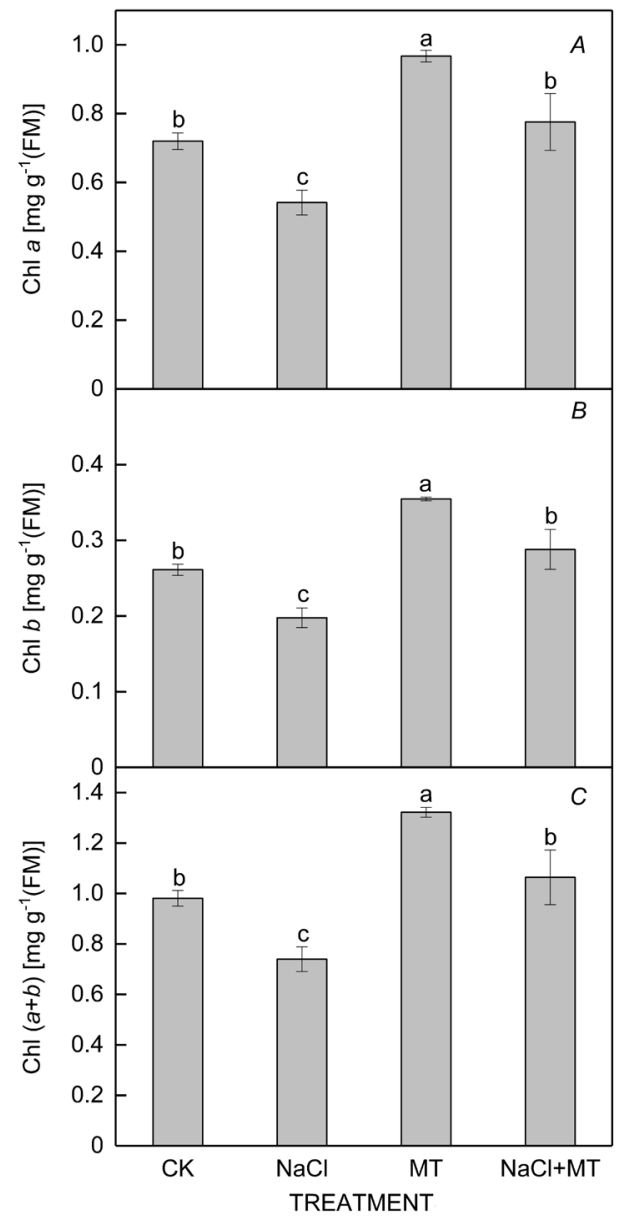

Fig. 3. Effect of melatonin on chlorophyll (Chl) $a(A), \mathrm{Chl} b(B)$, and $\mathrm{Chl}(a+b)(C)$ contents of sweet corn leaves under salinity stress. $\mathrm{CK}$ - normal control; $\mathrm{NaCl}$ - treatment with $100 \mathrm{mM}$ $\mathrm{NaCl}$; MT - treatment with $100 \mu \mathrm{M}$ melatonin; $\mathrm{NaCl}+\mathrm{MT}-$ treatment with $100 \mathrm{mM} \mathrm{NaCl}$ plus $100 \mu \mathrm{M}$ melatonin. Values are expressed as mean $\pm \mathrm{SD}$ of three replicates. For each variable, means with different lowercase letters were significantly different $(P<0.05)$. accumulation of these compounds was partially reduced after the application of melatonin. The MDA and $\mathrm{H}_{2} \mathrm{O}_{2}$ contents under salinity stress were significantly higher compared to the control and reached 136.2 and $104.3 \%$, respectively. However, after treatment with melatonin, both MDA and $\mathrm{H}_{2} \mathrm{O}_{2}$ contents in the $\mathrm{NaCl}+\mathrm{MT}$ treatment decreased significantly by 31 and $23 \%$, respectively, compared to the seedlings subjected to $\mathrm{NaCl}$ stress alone (Fig. 4). These findings indicated that MT application partially but significantly inhibited salinity stress-induced increase in MDA and $\mathrm{H}_{2} \mathrm{O}_{2}$ in sweet corn seedlings.

Antioxidant enzyme activities: Compared to the control treatment, $\mathrm{NaCl}$ stress significantly increased SOD, POD, and CAT activities by $106.8,87.3$, and $72.2 \%$ respectively (Fig. 5). Under normal conditions, there were no significant differences in SOD and APX activities between the CK and MT-treated seedlings; however, the activities of POD and CAT in the MT group significantly increased by 68.5 and $51.5 \%$, respectively, compared to those in the CK group. Compared to salinity treatment alone, exogenous MT remarkably increased the SOD, POD, and CAT activities under salinity stress by 138.8 , 38.7 , and $32.0 \%$, respectively. Moreover, an increase of $2.1 \%$ was determined in the APX activities in $\mathrm{NaCl}+\mathrm{MT}$ treated seedlings, relative to those treated only with $\mathrm{NaCl}$. These results indicated that SOD, POD, and CAT activities in leaves improved under salinity stress and that external supplementation of MT further enhanced SOD, POD, and CAT activities compared to the seedlings treated only with $\mathrm{NaCl}$. Exogenous MT treatment of sweet corn seedlings did not alter APX activities under normal or salinity conditions.

\section{Discussion}

Salinity stress is one of the most common stresses hampering plant growth and restricting crop production on large agricultural lands (Ahammed et al. 2018, Kaur et al. 2018). It causes ROS imbalance and affects photosynthesis, cell membrane integrity, and enzyme activity in plants (Khaliq et al. 2015, Yi et al. 2018). In this study, we found that almost all growth parameters decreased significantly

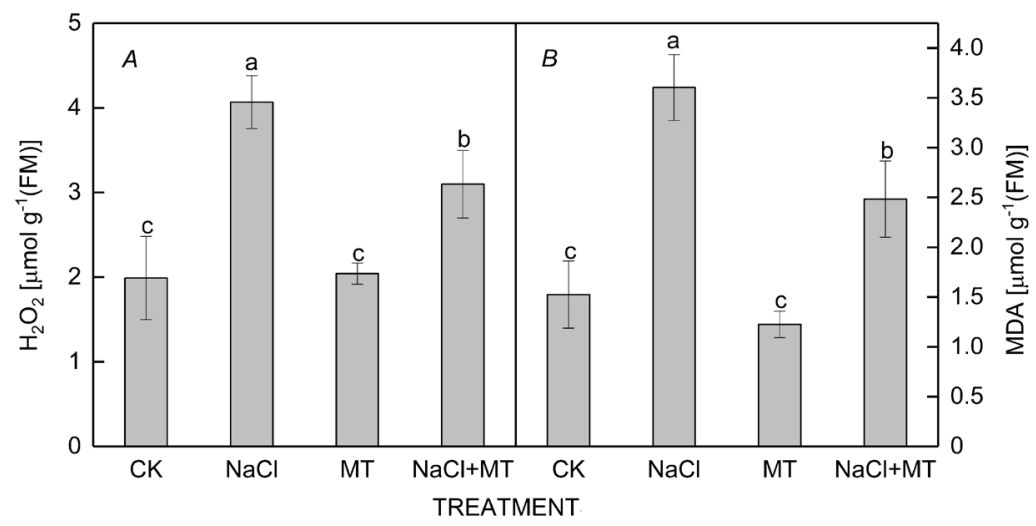

Fig. 4. Effect of melatonin on the $\mathrm{H}_{2} \mathrm{O}_{2}(A)$ and malondialdehyde (MDA) $(B)$ contents of sweet corn leaves under salinity stress. CK normal control; $\mathrm{NaCl}$ - treatment with $100 \mathrm{mM}$ $\mathrm{NaCl}$; MT - treatment with $100 \mu \mathrm{M}$ melatonin; $\mathrm{NaCl}+\mathrm{MT}$ - treatment with $100 \mathrm{mM} \mathrm{NaCl}$ plus $100 \mu \mathrm{M}$ melatonin. Values are expressed as mean $\pm \mathrm{SD}$ of three replicates. For each variable, means with different lowercase letters were significantly different $(P<0.05)$. 


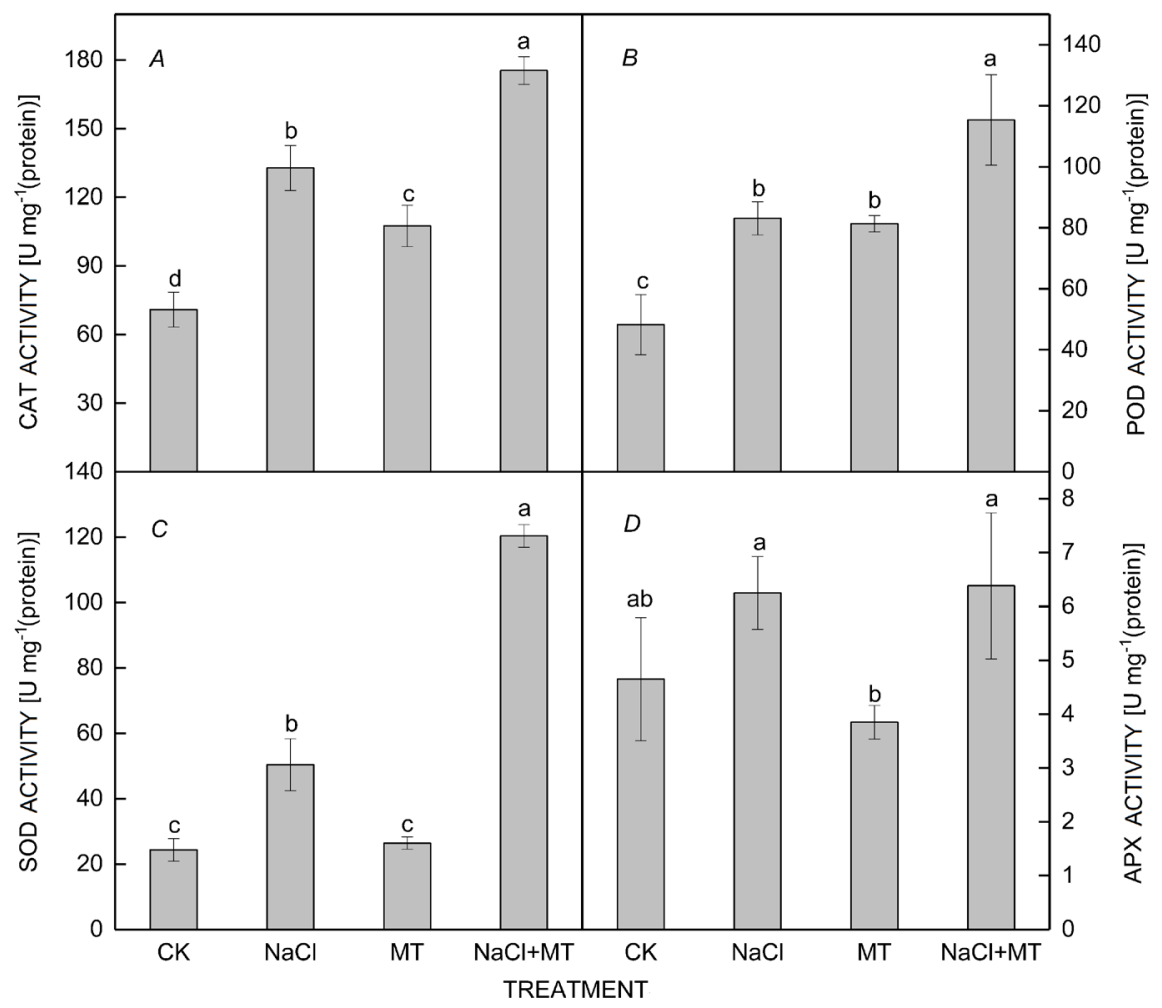

Fig. 5. Effect of melatonin on the activities of catalase (CAT) $(A)$, peroxidase $(\mathrm{POD})(B)$, superoxide dismutase (SOD) $(C)$, and ascorbate peroxidase (APX) $(D)$ of sweet corn leaves under salinity stress. CK normal control; $\mathrm{NaCl}$ - treatment with $100 \mathrm{mM} \mathrm{NaCl}$; MT - treatment with $100 \mu \mathrm{M}$ melatonin; $\mathrm{NaCl}+$ MT - treatment with $100 \mathrm{mM} \mathrm{NaCl}$ plus $100 \mu \mathrm{M}$ melatonin. Values are expressed as mean $\pm \mathrm{SD}$ of three replicates. For each variable, means with different lowercase letters were significantly different $(P<0.05)$.

during the $\mathrm{NaCl}$ treatment alone, whereas the application of melatonin significantly alleviated the decrease of the shoot and root FM and DM (Table 1). Previous studies suggest that melatonin, as a growth regulator, is related to different abiotic stresses in plants and has a positive effect on the growth of several plants (Arnao and HernándezRuiz 2014, Ye et al. 2020). We showed that exogenous $100 \mu \mathrm{M}$ MT could effectively increase the growth, and shoot and root FM and DM of maize under salinity stress. It suggested that exogenous MT possesses the ability to alleviate the salinity stress-inhibited growth and development in maize seedlings to a certain extent.

Plant photosynthesis is a complex physiological process, which is easily affected by environmental conditions (Sterling et al. 2019, Zhang et al. 2019). The primary limiting factor for photosynthesis upon exposure to salinity is the closure of stomata. Salinity stress leads to a decrease in stomatal conductance, which results in photosynthesis depression (Meloni et al. 2003). In this study, salinity stress significantly decreased $P_{\mathrm{N}}, E, g_{\mathrm{s}}, P_{\mathrm{N}} /$ $C_{\mathrm{i}}$, and WUE, and increased $C_{\mathrm{i}}$ in sweet corn seedlings, indicating that the reason for the decline in photosynthesis was changed from stomatal to nonstomatal limitation, in addition, salinity stress inhibited photosynthetic rate, resulting in excessive absorbed light energy, providing energy for ROS accumulation, thus causing damage to the photosynthetic apparatus, which in turn led to the weakening of carbon assimilation. However, after the addition of exogenous melatonin under salinity stress, $C_{\mathrm{i}}$ decreased significantly, whereas $P_{\mathrm{N}}$ and $g_{\mathrm{s}}$ increased, suggesting that exogenous melatonin could improve stomatal function and the photosynthetic capacity of mesophyll cells under salinity stress, which was consistent with the results of the study by Flexas and Medrano (2002). Moreover, exogenous MT treatment significantly increased $E, P_{\mathrm{N}} / C_{\mathrm{i}}$, and WUE under salinity stress, indicating its ability to increase the water absorptivity of plants and alleviate the decline in photosynthetic activity under salinity stress. Our results are in agreement with those of Liu et al. (2020), who reported a similar increase in these factors in melatonin-treated tobacco seedlings grown under stress conditions.

Chl fluorescence parameters reflect the ability of plants to absorb and transform light energy and help reveal changes in plant gas-exchange parameters (Moghadam et al. 2020). Previous studies have shown that exogenous melatonin can improve the light-use efficiency of watermelon under salinity stress (Li et al. 2017) and pea under paraquat stress (Szafrańska et al. 2016). In the current study, $\mathrm{F}_{\mathrm{v}} / \mathrm{F}_{\mathrm{m}}, \mathrm{q}_{\mathrm{p}}, \Phi_{\mathrm{PSII}}$, and ETR of sweet corn seedlings decreased, whereas NPQ increased under salinity stress, indicating that photoinhibition caused by stress and the electron transfer of photosynthetic electrons was blocked, and the efficiency of photosynthetic pigments converting light energy into chemical energy decreased. Pretreatment with exogenous melatonin under salinity stress could improve $\mathrm{F}_{\mathrm{v}} / \mathrm{F}_{\mathrm{m}}, \Phi_{\mathrm{PSII}}, \mathrm{q}_{\mathrm{P}}$, and ETR of the leaves of sweet corn seedlings, indicating that exogenous melatonin could improve the photochemical activity of photosystem reaction center of sweet corn seedlings under salinity stress, protect PSII from excessive energy damage, and enhance the stability of photosystem reaction center, which is conducive to the conversion of light energy into chemical energy, thus providing sufficient energy 
for carbon assimilation and effectively alleviating the inhibition of photosynthesis in sweet corn seedlings under salinity stress.

Chl is an important component of plants for the conversion of solar energy into chemical energy (Arnao and Hernández-Ruiz 2009); however, Chl is fragile and easily destroyed by ROS (Tan et al. 2012). Salinity stress can reduce $\mathrm{Chl}$ synthesis and accelerate the decomposition of Chl (Moghadam et al. 2020). As a strong oxidant, MT can inhibit the degradation of $\mathrm{Chl}$ and maintain the integrity of Chl under conditions of stress. MT treatment can significantly reduce the degradation of $\mathrm{Chl}$ in rice leaves under salinity stress, delay leaf senescence, and improve tolerance to salinity stress (Liang et al. 2015). In the current study, the Chl content in the leaves of sweet corn seedlings significantly decreased under salinity stress but the Chl content significantly increased with a foliar application of exogenous melatonin. This indicated that exogenous MT treatment enhanced the photosynthetic pigment-synthesis pathway and slowed the decomposition rate of maize leaf Chl under salinity stress.

The cell membrane is selectively permeable to substances, which is the basis of maintaining a normal cellular environment and metabolism. Under stress, excessive free radicals in plant cells can cause lipid peroxidation of membranes and damage the membrane system (Cao et al. 2019, Khan et al. 2020). An excessive accumulation of ROS occurs during stress in plants. $\mathrm{H}_{2} \mathrm{O}_{2}$ contents are a suitable indicator to determine the scavenging of ROS under stress (Ahmed et al. 2002). MDA is used as an index of lipid peroxidation, which reflects membrane injury (Zhang et al. 2014). The accumulation of $\mathrm{H}_{2} \mathrm{O}_{2}$ resulted in lipid peroxidation, which causes membrane damage (Al-Mureish et al. 2014). Melatonin treatment effectively inhibits the accumulation of $\mathrm{H}_{2} \mathrm{O}_{2}$ and MDA in cucumber seedlings under salinity stress (Wang et al. 2016). In our study, we found that $\mathrm{H}_{2} \mathrm{O}_{2}$ and MDA contents increased under salinity stress, suggesting cell membrane damage; however, $\mathrm{H}_{2} \mathrm{O}_{2}$ and MDA contents decreased significantly when exogenous melatonin was added under salinity stress. A reduction of $\mathrm{H}_{2} \mathrm{O}_{2}$ and MDA suggested that exogenous melatonin showed the protective effect against membrane damage under salinity stress.

To reduce oxidative stress, plants possess defense systems to scavenge excessive ROS. The antioxidant enzyme system, comprising SOD, POD, CAT, and APX, is an important system that protects cells from injury, thereby maintaining the balance of ROS in cells, slowing membrane lipid peroxidation, and resisting stress. As an antioxidant, melatonin plays a role in reducing oxidative stress in plants resulting from environmental stress (Rodriguez et al. 2004). Choi et al. (2011) and Wang et al. (2013) suggested that MT could directly scavenge ROS, maintain stable concentrations of $\mathrm{H}_{2} \mathrm{O}_{2}$, and improve CAT and POD activities. In our study, the SOD, POD, and CAT activities were found to increase significantly under salinity stress. APX activity also increased to a certain extent, but this change was not statistically significant. Moreover, the activities of these enzymes further increased when melatonin was applied under salinity stress. Collectively, our findings suggested that MT may indirectly scavenge $\mathrm{H}_{2} \mathrm{O}_{2}$ by enhancing the activities of CAT and POD. Our study confirmed that MT was involved in ROS scavenging under salinity stress. It suggested that exogenous MT might protect the plants from abiotic stress and prevent oxidative stress injuries at a cellular level. Therefore, the reversal of salinity stress by MT is attributed to its ability in improving antioxidant capacity and increasing the scavenging of ROS.

Conclusion: Salinity stress negatively influences plant height, biomass photosynthesis, and the chlorophyll fluorescence parameters in sweet corn seedlings. Foliar application of MT at the seedling stage improved photosynthesis, maintained the balance in ROS metabolism, and alleviated the damage caused by salinity stress during plant growth. Together, these results indicated that exogenous MT could alleviate the damage of sweet corn seedlings under salinity stress by enhancing the activities of antioxidant enzymes, reducing oxidative damage, and improving photosynthetic efficiency in leaves. Therefore, pretreatment with exogenous melatonin might be a suitable approach in improving the tolerance of sweet corn seedlings to salinity stress.

\section{References}

Abedi T., Pakniyat H.: Antioxidant enzyme changes in response to drought stress in ten cultivars of oilseed rape (Brassica napus L.). - Czech J. Genet. Plant Breed. 46: 27-34, 2010.

Afreen F., Zobayed S.M.A., Kozai T.: Melatonin in Glycyrrhiza uralensis: response of plant roots to spectral quality of light and UV-B radiation. - J. Pineal Res. 41: 108-115, 2006.

Ahammed G.J., Li Y., Li X. et al.: Epigallocatechin-3-gallate alleviates salinity-retarded seed germination and oxidative stress in tomato. - J. Plant Growth Regul. 37: 1349-1356, 2018.

Ahanger M.A, Alyemeni M.N, Wijaya L. et al:: Potential of exogenously sourced kinetin in protecting Solanum lycopersicum from $\mathrm{NaCl}$-induced oxidative stress through upregulation of the antioxidant system, ascorbate-glutathione cycle and glyoxalase system. - PLoS ONE 13: e0202175, 2018.

Ahmad P., Ahanger M.A., Alam P. et al.: Silicon (Si) supplementation alleviates $\mathrm{NaCl}$ toxicity in mung bean [Vigna radiata (L.) Wilczek] through the modifications of physiobiochemical attributes and key antioxidant enzymes. - J. Plant Growth Regul. 38: 70-82, 2019.

Ahmed S., Nawata E., Hosokawa M. et al.: Alterations in photosynthesis and some antioxidant enzymatic activities of mungbean subjected to waterlogging. - Plant Sci. 163: 117$123,2002$.

Alam P., Albalawi T.H., Altalayan F.H. et al.: 24-epibrassinolide (EBR) confers tolerance against $\mathrm{NaCl}$ stress in soybean plants by up-regulating antioxidant system, ascorbate-glutathione cycle, and glyoxalase system. - Biomolecules 9: 640, 2019.

Allen R.D.: Dissection of oxidative stress tolerance using transgenic plants. - Plant Physiol. 107: 1049-1054, 1995.

Al-Mureish K., Othman N.A.R.M., Al-Hakimi A.M.A.: Salicylic acid-mediated alleviation of cadmium toxicity in maize leaves. - J. Plant Sci. 2: 276-281, 2014.

Arnao M.B.: Phytomelatonin: discovery, content, and role in plants. - Adv. Bot. 2014: 815769, 2014. 
Arnao M.B., Hernández-Ruiz J.: Melatonin: plant growth regulator and/or biostimulator during stress? - Trends Plant Sci. 19: 789-797, 2014.

Arnao M.B., Hernández-Ruiz J.: Protective effect of melatonin against chlorophyll degradation during the senescence of barley leaves. - J. Pineal Res. 46: 58-63, 2009.

Bowler C., Van Montagu M., Inzé D.: Superoxide dismutase and stress tolerance. - Annu. Rev. Plant Phys. 43: 83-116, 1992.

Cai C., He S., An Y., Wang L.: Exogenous 5-aminolevulinic acid improves strawberry tolerance to osmotic stress and its possible mechanisms. - Physiol. Plantarum 168: 948-962, 2020.

Cao L., Jin X.J., Zhang Y.X.: Melatonin confers drought stress tolerance in soybean (Glycine max L.) by modulating photosynthesis, osmolytes, and reactive oxygen metabolism. Photosynthetica 57: 812-819, 2019.

Chaves M.M., Flexas J., Pinheiro C.J.: Photosynthesis under drought and salt stress: regulation mechanisms from whole plant to cell. - Ann. Bot.-London 103: 551-560, 2009.

Choi S., Dadakhujaev S., Ryu H. et al.: Melatonin protects against oxidative stress in granular corneal dystrophy type 2 corneal fibroblasts by mechanisms that involve membrane melatonin receptors. - J. Pineal Res. 51: 94-103, 2011.

Cui G., Zhao X., Liu S. et al.: Beneficial effects of melatonin in overcoming drought stress in wheat seedlings. - Plant Physiol. Bioch. 118: 138-149, 2017.

Farooq M., Hussain M., Wakeel A., Siddique K.H.M.: Salt stress in maize: effects, resistance mechanisms, and management. A review. - Agron. Sustain. Dev. 35: 461-481, 2015.

Feng Z.L., Liu J., Fu F.L., Li W.C.: Molecular mechanism of sweet and waxy in maize. - Int. J. Plant Breed. Genet. 2: 93-100, 2008.

Flexas J., Medrano H.: Drought-inhibition of photosynthesis in C3 plants: stomatal and non-stomatal limitations revisited. Ann. Bot.-London 89: 183-189, 2002.

Gao H.J., Yang H.Y., Bai J.P. et al.: Ultrastructural and physiological responses of potato (Solanum tuberosum L.) plantlets to gradient saline stress. - Front. Plant Sci. 5: 787, 2015.

Hodges D.M., DeLong J.M., Forney C.F., Prange R.K.: Improving the thiobarbituric acid-reactive-substances assay for estimating lipid peroxidation in plant tissues containing anthocyanin and other interfering compounds. - Planta 207: 604-611, 1999.

James M.G., Robertson D.S., Myers A.M.: Characterization of the maize gene sugary1, a determinant of starch composition in kernels. - Plant Cell 7: 417-429, 1995.

Jbir-Koubaa R., Charfeddine S., Ellouz W. et al.: Investigation of the response to salinity and to oxidative stress of interspecific potato somatic hybrids grown in a greenhouse. - Plant Cell. Tiss. Org. 120: 933-947, 2015.

Jiang C., Cui Q., Feng K. et al.: Melatonin improves antioxidant capacity and ion homeostasis and enhances salt tolerance in maize seedlings. - Acta Physiol. Plant. 38: 82, 2016.

Kaur H., Sirhindi G., Bhardwaj R. et al.: 28-homobrassinolide regulates antioxidant enzyme activities and gene expression in response to salt-and temperature-induced oxidative stress in Brassica juncea. - Sci. Rep.-UK 8: 8735, 2018.

Kaya C., Higgs D., Ashraf M. et al.: Integrative roles of nitric oxide and hydrogen sulfide in melatonin-induced tolerance of pepper (Capsicum annuum L.) plants to iron deficiency and salt stress alone or in combination. - Physiol. Plantarum 168: 256-277, 2020.

Kaya C., Okant M., Ugurlar F. et al.: Melatonin-mediated nitric oxide improves tolerance to cadmium toxicity by reducing oxidative stress in wheat plants. - Chemosphere 225: 627-
$638,2019$.

Khaliq A., Zia-ul-Haq M., Ali F. et al.: Salinity tolerance in wheat cultivars is related to enhanced activities of enzymatic antioxidants and reduced lipid peroxidation. - Clean Soil Air Water 43: 1248-1258, 2015.

Khan I., Raza M.A., Awan S.A. et al.: Amelioration of salt induced toxicity in pearl millet by seed priming with silver nanoparticles (AgNPs): The oxidative damage, antioxidant enzymes and ions uptake are major determinants of salt tolerant capacity. - Plant Physiol. Bioch. 156: 221-232, 2020.

Kohli S.K., Khanna K., Bhardwaj R. et al.: Assessment of subcellular ROS and NO metabolism in higher plants: multifunctional signaling molecules. - Antioxidants 8: 641, 2019.

Lee H.Y., Back K.: Melatonin plays a pivotal role in conferring tolerance against endoplasmic reticulum stress via mitogenactivated protein kinases and bZIP60 in Arabidopsis thaliana. - Melatonin Res. 1: 94-108, 2018.

Li C., Wang P., Wei Z. et al.: The mitigation effects of exogenous melatonin on salinity-induced stress in Malus hupehensis. J. Pineal Res. 53: 298-306, 2012.

Li H., Chang J., Chen H. et al.: Exogenous melatonin confers salt stress tolerance to watermelon by improving photosynthesis and redox homeostasis. - Front. Plant Sci. 8: 295, 2017.

Li J., Yang Y., Sun K. et al.: Exogenous melatonin enhances cold, salt and drought stress tolerance by improving antioxidant defense in tea plant (Camellia sinensis (L.) O. Kuntze). Molecules 24: 1826, 2019.

Li R., Shang H., Wu H. et al.: Thermal inactivation kinetics and effects of drying methods on the phenolic profile and antioxidant activities of chicory (Cichorium intybus L.) leaves. - Sci. Rep.-UK 8: 9529, 2018.

Liang C., Zheng G., Li W. et al.: Melatonin delays leaf senescence and enhances salt stress tolerance in rice. - J. Pineal Res. 59: 91-101, 2015.

Liang D., Ni Z., Xia H. et al.: Exogenous melatonin promotes biomass accumulation and photosynthesis of kiwifruit seedlings under drought stress. - Sci. Hortic.-Amsterdam 246: 34-43, 2019.

Lichtenthaler H.K., Wellburn A.R.: Determinations of total carotenoids and chlorophylls $a$ and $b$ of leaf extracts in different solvents. - Biochem. Soc. T. 11: 591-592, 1983.

Liu L., Li D., Ma Y. et al.: Combined application of arbuscular mycorrhizal fungi and exogenous melatonin alleviates drought stress and improves plant growth in tobacco seedlings. J. Plant Growth Regul., 2020.

Liu Z., Cai J.S, Li J.J. et al.: Exogenous application of a low concentration of melatonin enhances salt tolerance in rapeseed (Brassica napus L.) seedlings. - J. Integr. Agr. 17: 328-335, 2018.

Mahajan S.G., Nandre V.S., Salunkhe R.C. et al.: Chemotaxis and physiological adaptation of an indigenous abiotic stress tolerant plant growth promoting Pseudomonas stutzeri: Amelioration of salt stress to Cicer arietinum. - Biocatal. Agric. Biotechnol. 27: 101652, 2020.

Martinez V., Nieves-Cordones M., Lopez-Delacalle M. et al.: Tolerance to stress combination in tomato plants: New insights in the protective role of melatonin. - Molecules 23: $535,2018$.

Meloni D.A., Oliva M.A., Martinez C.A., Cambraia J.: Photosynthesis and activity of superoxide dismutase, peroxidase and glutathione reductase in cotton under salt stress. - Environ. Exp. Bot. 49: 69-76, 2003.

Misra A.N., Sahu S.M., Misra M. et al.: Sodium chloride induced changes in leaf growth, and pigment and protein contents in two rice cultivars. - Biol. Plantarum 39: 257-262, 1997. 
Mittler R.: Oxidative stress, antioxidants and stress tolerance. Trends Plant Sci. 7: 405-410, 2002.

Moghadam N.K., Motesharezadeh B., Maali-Amiri R. et al.: Effects of potassium and zinc on physiology and chlorophyll fluorescence of two cultivars of canola grown under salinity stress. - Arab. J. Geosci. 13: 771, 2020.

Nakano Y., Asada K.: Hydrogen peroxide is scavenged by ascorbate-specific peroxidase in spinach chloroplasts. - Plant Cell Physiol. 22: 867-880, 1981.

Perera-Castro A.V., Brito P., González-Rodríguez A.M.: Change in thermic limits and acclimation assessment for an alpine plant by chlorophyll fluorescence analysis: $\mathrm{F}_{\mathrm{v}} / \mathrm{F}_{\mathrm{m}} v$ s. $\mathrm{R}_{\mathrm{fd}}$. Photosynthetica 56: 527-536, 2018.

Quintero J.M., Fournier J.M., Benlloch M.: $\mathrm{Na}^{+}$accumulation in shoot is related to water transport in $\mathrm{K}^{+}$-starved sunflower plants but not in plants with a normal $\mathrm{K}^{+}$status. - J. Plant Physiol. 164: 60-67, 2007.

Rao M.V., Paliyath G., Ormrod D.P.: Ultraviolet-B- and ozoneinduced biochemical changes in antioxidant enzymes of Arabidopsis thaliana. - Plant Physiol. 110: 125-136, 1996.

Rodriguez C., Mayo J.C., Sainz R.M. et al.: Regulation of antioxidant enzymes: a significant role for melatonin. J. Pineal Res. 36: 1-9, 2004.

Sharma A., Zheng B.: Melatonin mediated regulation of drought stress: physiological and molecular aspects. - Plants-Basel 8: 190, 2019.

Sterling A., Rodríguez N., Quiceno E. et al.: Dynamics of photosynthetic responses in 10 rubber tree (Hevea brasiliensis) clones in Colombian Amazon: Implications for breeding strategies. - PLoS ONE 14: e0226254, 2019.

Szafrańska K., Reiter R.J., Posmyk M.M.: Melatonin application to Pisum sativum L. seeds positively influences the function of the photosynthetic apparatus in growing seedlings during paraquat-induced oxidative stress. - Front. Plant Sci. 7: 1663, 2016.

Tan D.X., Hardeland R., Manchester L.C. et al.: Functional roles of melatonin in plants, and perspectives in nutritional and agricultural science. - J. Exp. Bot. 63: 577-597, 2012.

Tan D.X., Manchester L.C., Reiter R.J. et al.: Melatonin directly scavenges hydrogen peroxide: a potentially new metabolic pathway of melatonin biotransformation. - Free Radical Bio. Med. 29: 1177-1185, 2000.

Tyagi S., Shumayla., Verma P.C. et al.: Molecular characterization of ascorbate peroxidase (APX) and APX-related (APX-R) genes in Triticum aestivum L. - Genomics 112: 4208-4223,
2020.

Wang C.Y.: Effect of temperature preconditioning on catalase, peroxidase, and superoxide dismutase in chilled zucchini squash. - Postharvest Biol. Tec. 5: 67-76, 1995.

Wang L.Y., Liu J.L., Wang W.X., Sun Y.: Exogenous melatonin improves growth and photosynthetic capacity of cucumber under salinity-induced stress. - Photosynthetica 54: 19-27, 2016.

Wang P., Sun X., Li C. et al.: Long-term exogenous application of melatonin delays drought-induced leaf senescence in apple. - J. Pineal Res. 54: 292-302, 2013.

Xia X.J., Wang Y.J., Zhou Y.H. et al.: Reactive oxygen species are involved in brassinosteroid-induced stress tolerance in cucumber. - Plant Physiol. 150: 801-814, 2009.

Yang X.L., Xu H., Li D. et al.: Effect of melatonin priming on photosynthetic capacity of tomato leaves under lowtemperature stress. - Photosynthetica 56: 884-892, 2018.

Ye J., Yang W., Li Y. et al.: Seed pre-soaking with melatonin improves wheat yield by delaying leaf senescence and promoting root development. - Agronomy 10: 84, 2020.

Yi Z., Li S., Liang Y. et al.: Effects of exogenous spermidine and elevated $\mathrm{CO}_{2}$ on physiological and biochemical changes in tomato plants under iso-osmotic salt stress. - J. Plant Growth Regul. 37: 1222-1234, 2018.

Yu X., Liang C., Chen J. et al.: The effects of salinity stress on morphological characteristics, mineral nutrient accumulation and essential oil yield and composition in Mentha canadensis L. - Sci. Hortic.-Amsterdam 197: 579-583, 2015.

Zhang H.J., Zhang N., Yang R.C. et al.: Melatonin promotes seed germination under high salinity by regulating antioxidant systems, $\mathrm{ABA}$ and $\mathrm{GA}_{4}$ interaction in cucumber (Cucumis sativus L.). - J. Pineal Res. 57: 269-279, 2014.

Zhang M., He S., Zhan Y. et al.: Exogenous melatonin reduces the inhibitory effect of osmotic stress on photosynthesis in soybean. - PLoS ONE 14: e0226542, 2019.

Zhang N., Sun Q., Zhang H. et al.: Roles of melatonin in abiotic stress resistance in plants. - J. Exp. Bot. 66: 647-656, 2015.

Zhang N., Zhao B., Zhang H.J. et al.: Melatonin promotes waterstress tolerance, lateral root formation, and seed germination in cucumber (Cucumis sativus L.). - J. Pineal Res. 54: 15-23, 2013.

Zou J.N., Jin X.J., Zhang Y.X. et al.: Effects of melatonin on photosynthesis and soybean seed growth during grain filling under drought stress. - Photosynthetica 57: 512-520, 2019.

(C) The authors. This is an open access article distributed under the terms of the Creative Commons BY-NC-ND Licence. 